\title{
EFFECT OF MITE INFESTATION ON THE ANTI-PREDATOR DEFENSES OF AN INSECT ${ }^{1}$
}

\author{
By Craig laMunyon and Thomas Eisner \\ Section of Neurobiology \& Behavior, Cornell University, \\ Seeley G. Mudd Hall, Ithaca, New York 14853
}

Mites ectoparasitic on insects extract body fluids from their hosts. In the extreme, the infestations can be lethal, as has been shown with some nymphal and adult insects (Young and Welbourn 1987) and insect eggs (Sharma et al. 1983), but they can also be less harmful. Many erythraeid mites gorge on an insect and drop off, leaving the host seemingly unaffected (Southcott 1961; Treat 1975). However, given that mites inevitably remove potentially essential nutrients from the host (Cheng 1973), even transient infestations should leave insects weakened or otherwise adversely affected. The question was whether sublethal infestations could be indirectly lethal, by decreasing the host's ability to withstand secondary hazards. We here present data on the effect of erythraeid mite infestation on an homopteran insect, the flatid Ormenaria rufifascia. We show that while the infestations can be fatal, they are encumbering even when non-fatal, in that they impair the defenses used by the host against predation.

The life cycle of Ormenaria rufifascia has recently been described (Wilson and Tsai 1984). Our study was done with Ormenaria nymphs only, since these were the stages that we found to be miteinfested. The defenses of nymphal Ormenaria, which will be described in detail elsewhere, are twofold. One relates to the nymph's production of wax, the other to its ability to leap. The wax production involves secretion of lengthy (presumably crystalline) filaments, which emerge as tufts from glandular openings on the abdomen. There are four primary tufts, two posteriorly-extending caudal tufts, and two posterolateral tufts (Fig. 1C). The nymphs live on the surface of palmetto fronds. By occasionally wiping their caudal filaments on the frond surface in their immediate surrounds, they create

\footnotetext{
'Paper no. 94 in the series Defense Mechanisms of Arthropods; no. 93 is Dean et al., Science, in press.

*Manuscript received by the editor March 3, 1990
} 

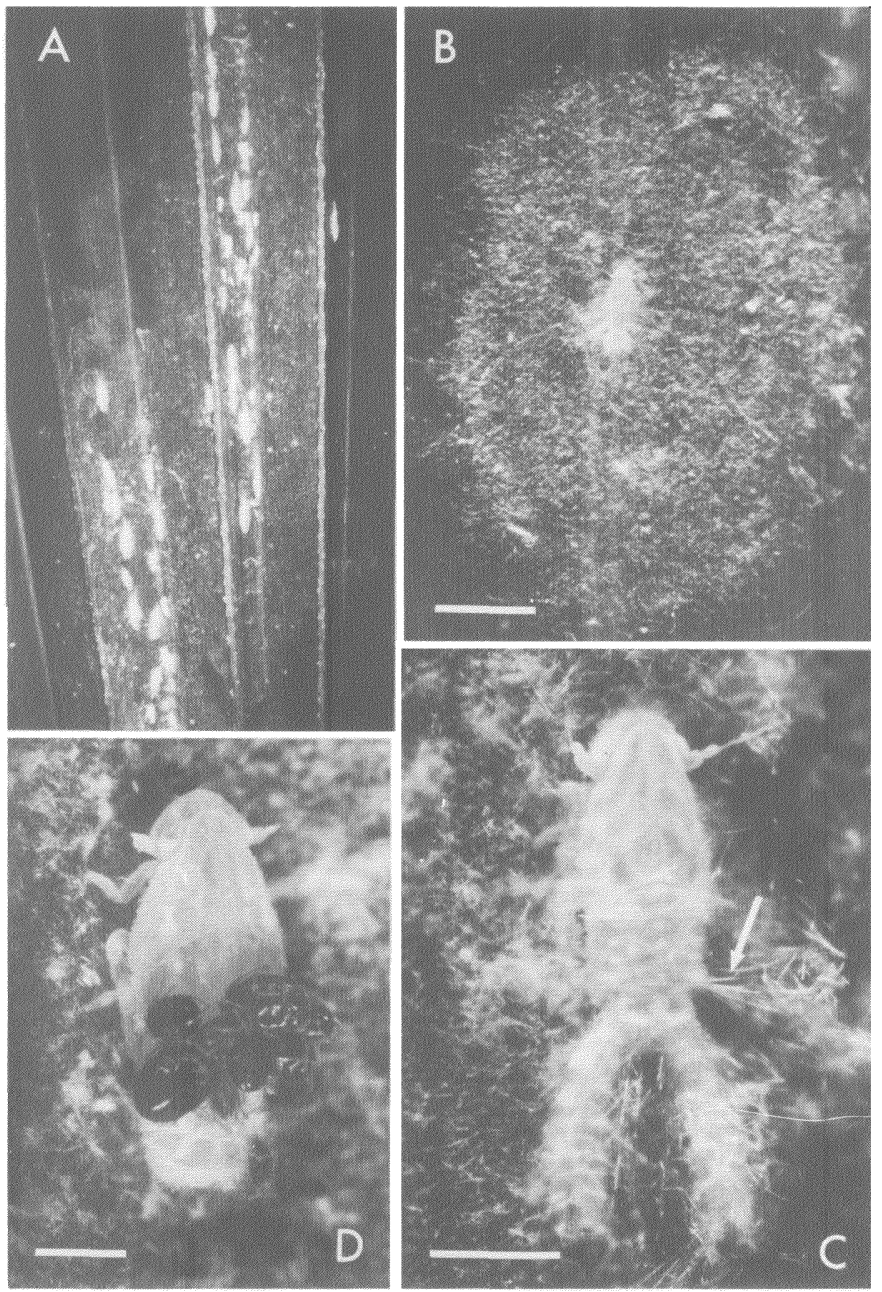

Fig. 1. A, Large "colony" of Ormenaria rufifascia nymphs on frond of cabbage palm (Sabal palmetto); 27 nymphs are shown, of which 8 bore infesting mites (5 nymphs with 1 mite; 1 with 2 mites; 1 with 3 mites; the infestations were resolved by microscopic examination of the original color transparency from which this photograph was made). B, Single nymph, on its wax pad. C, Nymph showing the two caudal and two lateral wax tufts (arrow denotes right lateral tuft). D, Late instar nymph bearing 9 Caeculisoma mites. Such high levels of infestation are exceptional. The individual shown died shortly after being photographed. Bars: $B=5 \mathrm{~mm} ; \mathrm{C}, \mathrm{D}=$ $0.5 \mathrm{~mm}$. 
zones of loosely matted wax powder (essentially broken up wax filaments), which take the form of conspicuous white pads (Fig. 1A, B). The nymphs live within these pads, singly or in small to large groups. When disturbed by direct contact, they leap away. In so doing they thrust themselves forward into the air by pushing against the substrate with their hind legs, which are armed with special anchoring spines for the purpose (T. Eisner, I. T. Baldwin, M. Eisner, unpublished).

The wax pads act as deterrents to ambulatory insect predators. Coccinellid beetle larvae, which ordinarily are unreluctant to walk on palm fronds, turn away when they come in contact with the edges of a pad. While food items offered as bait beside pads are eaten by such larvae, comparable items placed within the pads are ignored (T. Eisner, unpublished).

The leaps, by virtue of their abruptness and kinetic force, must themselves be defensive. Even early instar Ormenaria nymphs can jump distances of over $20-30 \mathrm{~cm}$. The body coating of wax can also convey protection. Nymphs which in the process of leaping strike spider webs (which are ubiquitous in Ormenaria's habitat) tend not to be detained since they fail to adhere to the web's viscid threads. The wax also prevents the nymphs from becoming wetted when they leap into water or onto a wet plant surface. They float and literally paddle their way out of the liquid with their legs (T. Eisner, I. T. Baldwin, unpublished).

The mite that we found to infest Ormenaria was a red velvet mite of the genus Caeculisoma (family Erythraeidae). We assessed two effects of the mite upon the host: (1) the effect on wax production, and (2) the effect on the proness to leap. We also report some observations on the vulnerability of Ormenaria to predation by green lacewing larvae (family Chrysopidae).

\section{Materials AND Methods}

Our study was done in March 1989, at two central Florida sites in Highland County: the Highlands Hammock State Park, near Sebring, and the Archbold Biological Station, south of Lake Placid. Ormenaria were noted on three palms: saw palmetto (Serenoa repens), scrub palmetto (Sabal etonia), and cabbage palm (Sabal palmetto). In the sandy scrub habitat prevailing at the Archbold Station, Ormenaria occurred on saw palmetto and scrub palmetto, 
but infrequently and on small wax pads only, with but one or few nymphs per pad. In the hammock habitat of the State Park the nymphs occurred primarily on the large-fronded cabbage palm, on which the pads were often of substantial expanse (longest dimension sometimes over $30 \mathrm{~cm}$ ), and inhabited by "colonies" of dozens of nymphs of various sizes (Fig. 1A). As we know from previous observations, the adult Ormenaria, which are free-flying, do not emerge until later in the season (see also Wilson and Tsai 1984).

Infested Ormenaria were most common in the State Park colonies. The red color of the mites made infested individuals conspicuous from a distance. Larger colonies sometimes contained infested nymphs in numbers (see legend to fig. 1A). Mites usually occurred singly on nymphs (Fig. 2B, C), but larger nymphs sometimes bore two or even more mites (Fig. 1D). Even small nymphs, judged to be second instar, were sometimes infested. No adults of the mite were obtained, precluding identification to species. Voucher specimens of immature stages are being deposited under our lot number 1189 in the Cornell Entomology collection.

Wax production. To measure wax production, infested $(\mathrm{N}=22$, bearing 1 or 2 mites) and uninfested $(\mathrm{N}=21)$ Ormenaria nymphs (late instar) were first dewaxed by pulling away the wax tufts with fine forceps. They were then placed on freshly-cut rectangular pieces (approximately $5 \times 10 \mathrm{~cm}$ ) of saw palmetto frond (Serenoa repens), upon which they became readily established. The frond pieces were kept fresh by covering the proximal cut edge with strips of wetted tissue paper. The nymphs were checked at 12 and 60 hours, under stereomicroscopic magnification, for length of the caudal tufts relative to abdomen length (e.g. tuft length half that of abdomen $=0.5$ ). Two infested and 3 uninfested nymphs left their frond pieces in the 12-60 $\mathrm{hr}$ interval and were therefore excluded from the $60 \mathrm{hr}$ check. Seven infested individuals and one uninfested individual died and were also excluded from the $60 \mathrm{hr}$ check. Some of the nymphs laid down incipient wax pads. In such individuals, in which the two caudal tufts were sometimes of disparate length as a consequence of uneven use for pad construction, the longer tuft was chosen for measurement of length. Incidence of pad construction was itself recorded, as well as incidence of mite detachment, molting, and host mortality.

Jumping tendency. To determine whether infestation impairs jumping ability, infested and uninfested Ormenaria were directly 

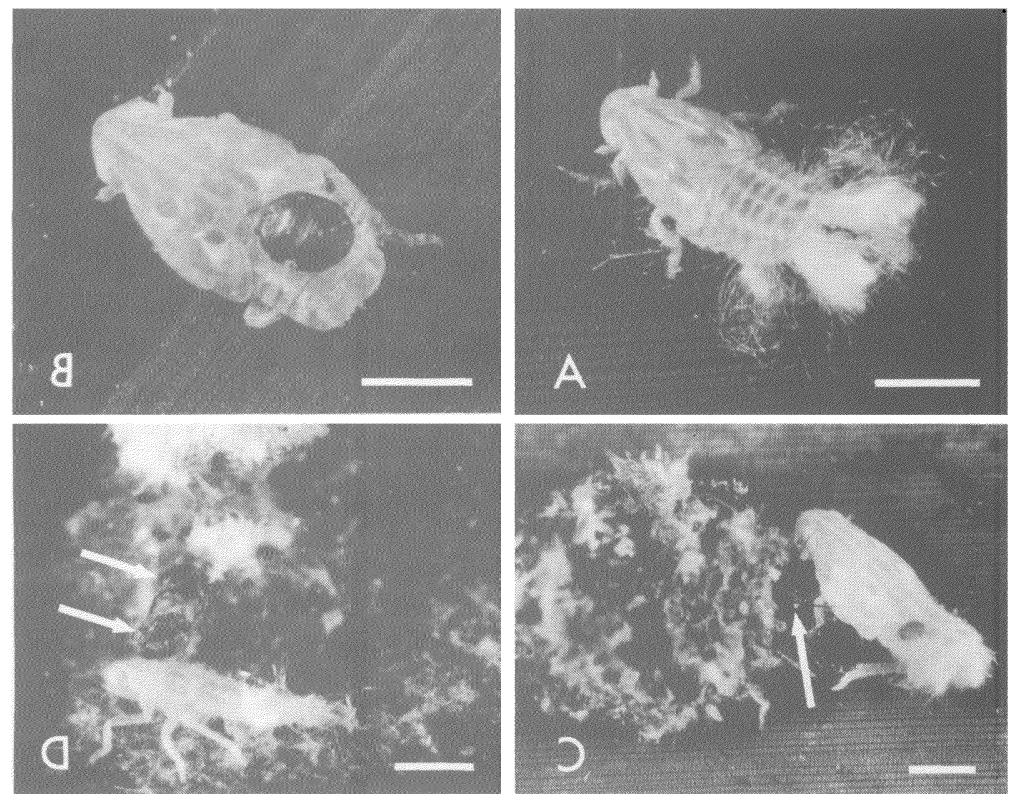

Fig. 2. A-B, Experimental Ormenaria nymphs that were dewaxed $60 \mathrm{hr}$ beforehand. The uninfested individual (A) has grown wax tufts, while the infested individual (B) has not. Details in text. C, Trash-carrying chrysopid larva (Ceraeochrysa smithi) feeding on an infested nymph; the small mite is visible on the nymph's abdomen; arrow denotes head of chrysopid. D, C. smithi larva feeding on a nymph's parasitic mite; the upper and lower arrows denote respectively the chrysopid's head and the mite. $B a r=1 \mathrm{~mm}$

prodded with a hand-held, pointed steel probe, touched dorsally to the posterior half of their body. The tests were carried out in the field, with individuals from medium-sized to large colonies on cabbage palm at the State Park. Individuals that failed to respond to two consecutive proddings applied seconds apart were scored as non-respondents. A total of 34 infested individuals (from 12 colonies) were thus tested. The uninfested controls were in part $(\mathrm{N}=$ 132) from the same 12 colonies, and in part $(N=186)$ from 22 colonies that were entirely mite-free.

Predation tests. A total of 19 singly and doubly infested nymphs, and 13 uninfested nymphs, were exposed to predation by second and third instar field-collected chrysopid larvae (Ceraeochrysa smithi). The tests were intended as preliminary to the development of a 
Z Mean Wax-Tuft Length (abdominal length equivalent +SEM)

$\square$ Incidence of Wax-pad Construction (\%)

Mortality (\%)

图 Molting (\%)

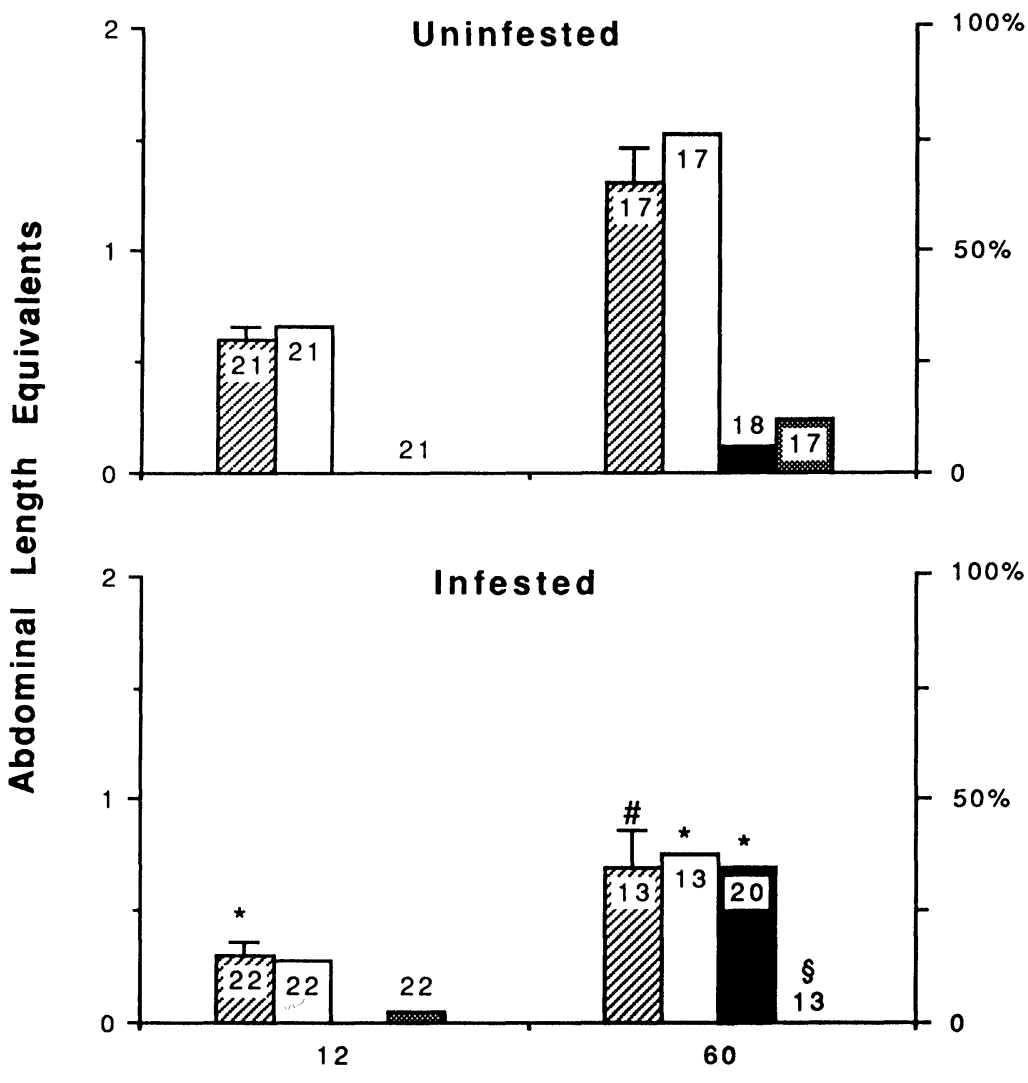

Time After Experimental Dewaxing (hr)

Fig. 3. Wax-tuft production, and incidence of wax-pad deposition, mortality, and molting, of infested and uninfested Ormenaria nymphs, at 12 and $60 \mathrm{hr}$ after experimental dewaxing. Numbers within/atop bars give sample sizes. Symbols indicate level of statistical difference from uninfested category $\left({ }^{*}=p<0.01 ; \S=p<0.02 ; \#=\right.$ $p<0.005$ ). Details in text. 
more rigid protocol, but further experimentation was precluded by our failure to collect chrysopids in sufficient numbers. Ormenaria were introduced in groups of four ( 2 infested; 2 uninfested) into a petri dish (bottom sand-blasted to provide a roughened ambulatory surface for the insects), containing during any one observation period from one to five chrysopid larvae. The tests were carried out over a period of days; observation periods were of an hour and longer. The double-paired offering of nymphal types was maintained constant, except during the initial observation periods. Nymphs were replaced by ones of their type (infested or uninfested) if they leapt away or were captured. They were also replaced in two cases where they lost their mites to predatory capture by a chrysopid and were not themselves caught thereafter by the chrysopid. Data were scored as fate of nymphs (captured, leapt away in response to chrysopid attack) and fate of mite.

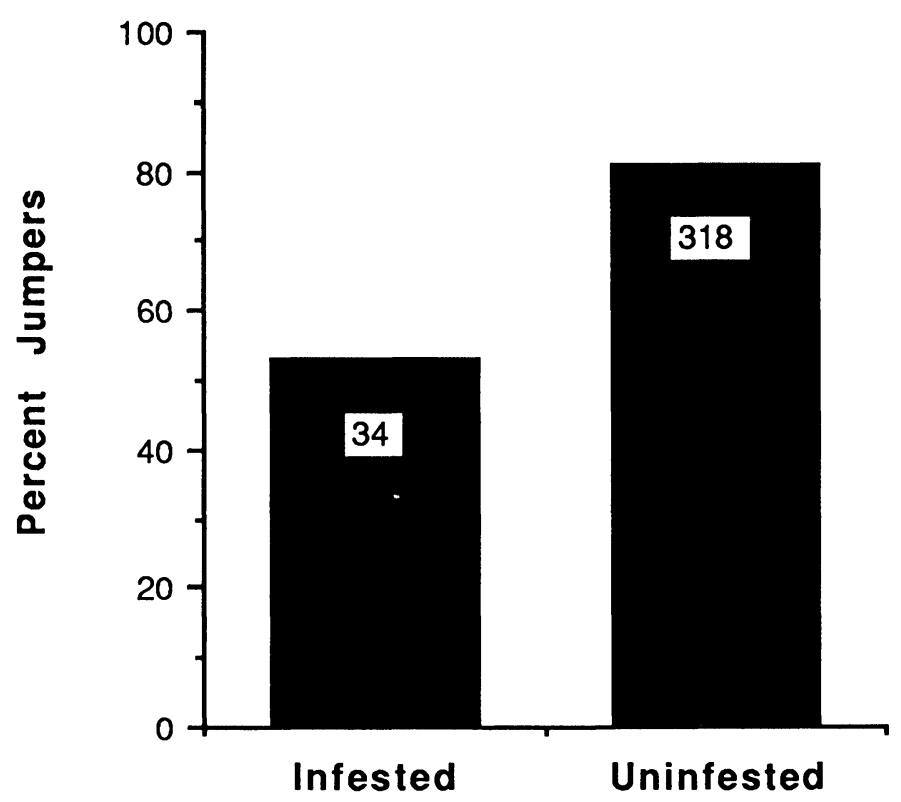

Fig. 4. Jumping propensity of infested and uninfested Ormenaria nymphs (difference is significant at $p<0.001$ ). Details in text. 


\section{RESULTS}

Wax production. Infestation evidently had an effect on wax production (Fig. 2A, B; Fig. 3). Uninfested individuals had longer caudal tufts $(12 \mathrm{hr}, \mathrm{p}<0.01 ; 60 \mathrm{hr}, \mathrm{p}<0.005 ; \mathrm{t}$-Test), and showed higher incidence of pad construction $(60 \mathrm{hr}, \mathrm{p}<0.01 ; \mathrm{t}-\mathrm{Test})$, and of molting $(60 \mathrm{hr}, \mathrm{p}<0.02 ; \mathrm{t}$-Test). Infested individuals also incurred higher mortality $(\mathrm{p}<0.01 ; \mathrm{t}-\mathrm{Test})$.

Although some mites dropped from their hosts during the course of the experiment, 9 of 13 infested individuals still bore mites at 60 hr. Infestation can evidently last longer than 2.5 days.

Jumping tendency. As is clear from Fig. 4, infested individuals had a lower propensity to leap ( $\mathrm{p}<0.001$; Z-Test for proportion comparison). The two categories of uninfested individuals did not differ in their jumping tendency $(p>0.4)$, justifying their treatment as a single category.

Predation tests. The data, too scant to merit statistical analysis, are suggestive at best (Table 1). While essentially the same fraction of infested and uninfested Ormenaria escaped attacks by jumping, a larger number of infested individuals was eaten (Fig. 2C). The captured nymphs were fully consumed by the chrysopids, which sucked out their contents, leaving only the skeletal remains, as they typically do with insect prey. Interestingly, on three occasions, a chrysopid seized the infesting mite rather than the Ormenaria host when it attacked (Fig. 2D). The mites were in all three cases eaten, but the Ormenaria escaped on two occasions, and was only in one instance itself taken after consumption of the mite.

\begin{tabular}{lcc}
\hline & Uninfested & Infested \\
Jumped & 8 & 11 \\
Eaten & 1 & 4 \\
Mites eaten & - & 3 \\
\# Tested & 13 & 19 \\
\hline
\end{tabular}

Table 1. Outcome of encounters of infested and uninfested Ormenaria nymphs with chrysopid larvae (Ceraeochrysa smithi). Details in text. 


\section{Discussion}

Caeculisoma infestation can evidently be fatal to Ormenaria, and detrimental even when non-fatal. Infested individuals produce less defensive wax and are less prone to leap away when disturbed. There can be little doubt, therefore, that non-fatal infestation can render Ormenaria more susceptible to predatory capture.

The experimentation with chrysopid predators was not nearly as extensive as we would have liked, but it did provide some indication that infested Ormenaria fare worse vis à vis chrysopids than uninfestèd ones. Under natural conditions one might expect infested individuals to be handicapped further by their reduced ability to lay down wax pads. This factor did not enter into our tests, where the chrysopids were offered Ormenaria away from their pads, in a glass arena. It has, in fact, been observed that early instar chrysopid larvae (Ceraeochrysa smithi) tend to desist from walking onto Ormenaria wax pads (M. Eisner, unpublished). In our judgment, the pads may be deterrent to a whole array of marauding arthropds, but this remains to be demonstrated.

Not unexpected was the finding that uninfested Ormenaria were equally responsive to prodding (that is, prone to jump), whether they were from colonies bearing infested individuals, or from ones that were entirely mite-free. We interpret this to indicate that physical "vigor" is intrinsically uniform from colony to colony, and that colonial mite distribution is not a function of inter-colony differences in such vigor. It would be interesting to know in this connection how Caeculisoma manage to mount a host that has the capacity to avoid being mounted by jumping away.

Of interest was the observation that the mites could themselves fall victim to predation. By "riding" exposed on the surface of the host, they incur the risk of seizure, such as actually occurred in the tests with chrysopids. Potentially more endangering, however, is their encumbrance of the host's defenses. By rendering the host more approachable and graspable, they clearly increase their own vulnerability as well. One wonders about the significance of the red color of the mites. Is the color aposematic, and are the mites perhaps unpalatable to predators other than chrysopids?

The notion that a parasite endangers itself by encumbering the host is certainly not new. Insect mites could quite generally be disadvantaged by impairment of the host. Noteworthy in this context is 
the case of ear-infesting mites of moths, which by unilaterally deafening their hosts could affect the latter's ability to evade echolocating bats (Treat 1975; Roeder 1967). Interestingly, the mites have a strategy for preventing infections from overtaking both ears, which would induce total deafness and even greater vulnerability (Treat 1975). In an exceptional case, where the mites infest both ears, they do so without necessarily destroying the acoustical apparatus (Treat 1977).

Under special circumstances, host impairment can be beneficial to a parasite. If, for completion of its life cycle, a parasite depends on ingestion of the intermediate host, it can obviously be to the parasite's advantage to handicap that host. Adaptive behavioral encumbrance of intermediate hosts has been demonstrated for a number of parasites (Curio 1988). Ants infested with the trematode Dicrocoelium dendriticum tend to cling to the top of blades of grass or herbs, a behavior that increases their likelihood of being eaten by mammalian grazers, the definitive hosts of the worm (Hohorst and Graefe 1961; Schneider and Hohorst 1971). We know of no documented cases of parasites that specifically inhibit the anti-predator defenses of their intermediate insect hosts, such as perhaps the chemical defenses, although we are tempted to predict that such cases must exist.

\section{SUMMARY}

A natural erythraeid mite infestation (Caeculisoma sp.) of a flatid homopteran (Ormenaria rufifascia) is described. Infested Ormenaria nymphs produce less defensive wax and are less prone to leap away when molested, effects that doubtless increase their vulnerability to predation.

\section{ACKNOWLEDGMENTS}

Study supported in part by grant AI-02908 from NIH, and by a Sigma Xi research grant to C. LaM. The investigation was undertaken as part of a student course, "Exploration, Discovery, and Followup", offered in March 1989 by Cornell University at the Archbold Biological Station, Lake Placid, Florida, where TE is a research associate. The staff of the Station, and that of the Highlands Hammock State Park, were most helpful. We thank Katherine 
Tauber for identifying the chrysopid, George Eickwort for identifying the mite, Mark Deyrup for scientific advice, and Maria Eisner for field assistance and preparation of illustrations.

\section{REFERENCES}

Cheng, T. C.

1973. General parasitology. Academic Press, New York.

Curio, E.

1988. Behavior and parasitism. Pages 149-160, in H. Mehlhorn (ed.) Parasitology in focus: Facts and Trends. Springer, New York.

Hohorst, W. AND G. Graefe

1961. Ameisen-obligatorische Zwischenwirte des Lanzettegels (Dicrocoelium dendriticum) Naturwiss. 48: 229-230.

ROEDER, K. D.

1967. Nerve Cells and Insect Behavior. Harvard Univ. Press, Cambridge, Massachusetts.

SCHNEIDER, G. AND W. Hohorst

1971. Wanderung der Metacercarien des lanzettegels in Ameisen. Naturwiss. 58: $327-328$.

Sharma, G. D., A. T. Drooz, and A. E. Treat

1983. A new species of Callidosoma (Acari: Prostigmata:Erythraeidae) parasite on adults of Anacamptodes vellivolata (Lepidoptera: Geometridae) as a larva, and a predator of egs of Lepidoptera as a deutonymph and adult. Ann. Entomol. Soc. Am. 76: 120-125.

Southсотт, R. V.

1961. Notes on the genus Cauculisoma (Acarina: Erythraeidae) with comments on the biology of the Erythraeoidea. Trans. R. Soc. South Austr. 84: $163-178$.

Treat, A. E.

1975. Mites of Moths and Butterflies. Cornell Univ. Press, Ithaca, New York. TreAt, A.

1977. Moth ear mites: new findings and a new species from North America. Acarologia 19: 183-200.

Wilson, S. W. AND J. H. TsaI

1984. Ormenaria rufifascia (Homoptera: Fulgoroidea: Flatidae): descriptions of nymphal instars and notes on field biology. N.Y. Entomol. Soc. 92: 307-315.

Young, O. P. AND W. C. Welbourn

1987. Biology of Lasioerythraeus johnstoni (Acari: Erythraeidae), ectoparasitic and predaceous on the Tarnished Plant Bug, Lygus linealaris (Hemiptera: Miridae), and other arthropods. Ann. Entomol. Soc. Am. 80: $243-250$. 

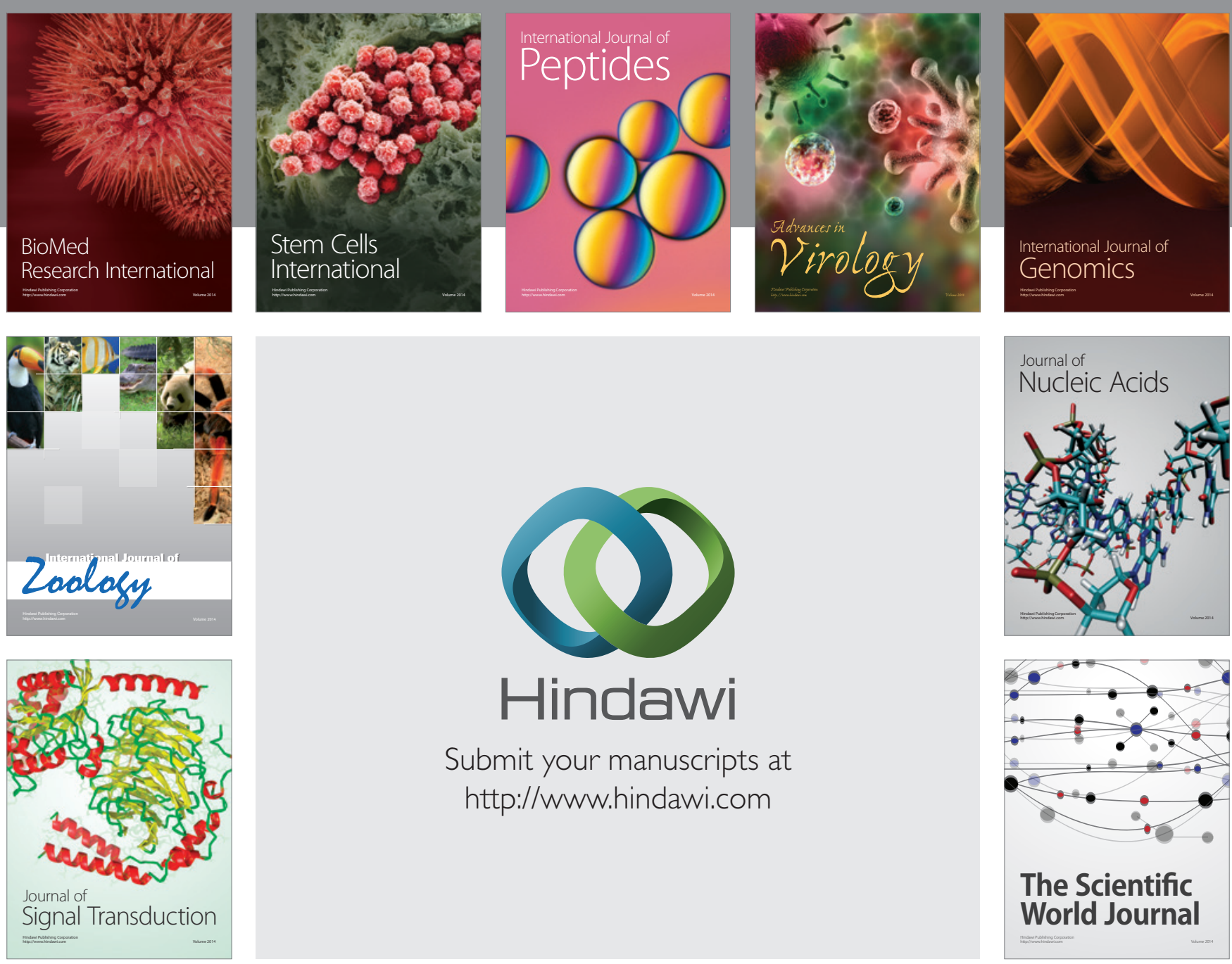

Submit your manuscripts at

http://www.hindawi.com
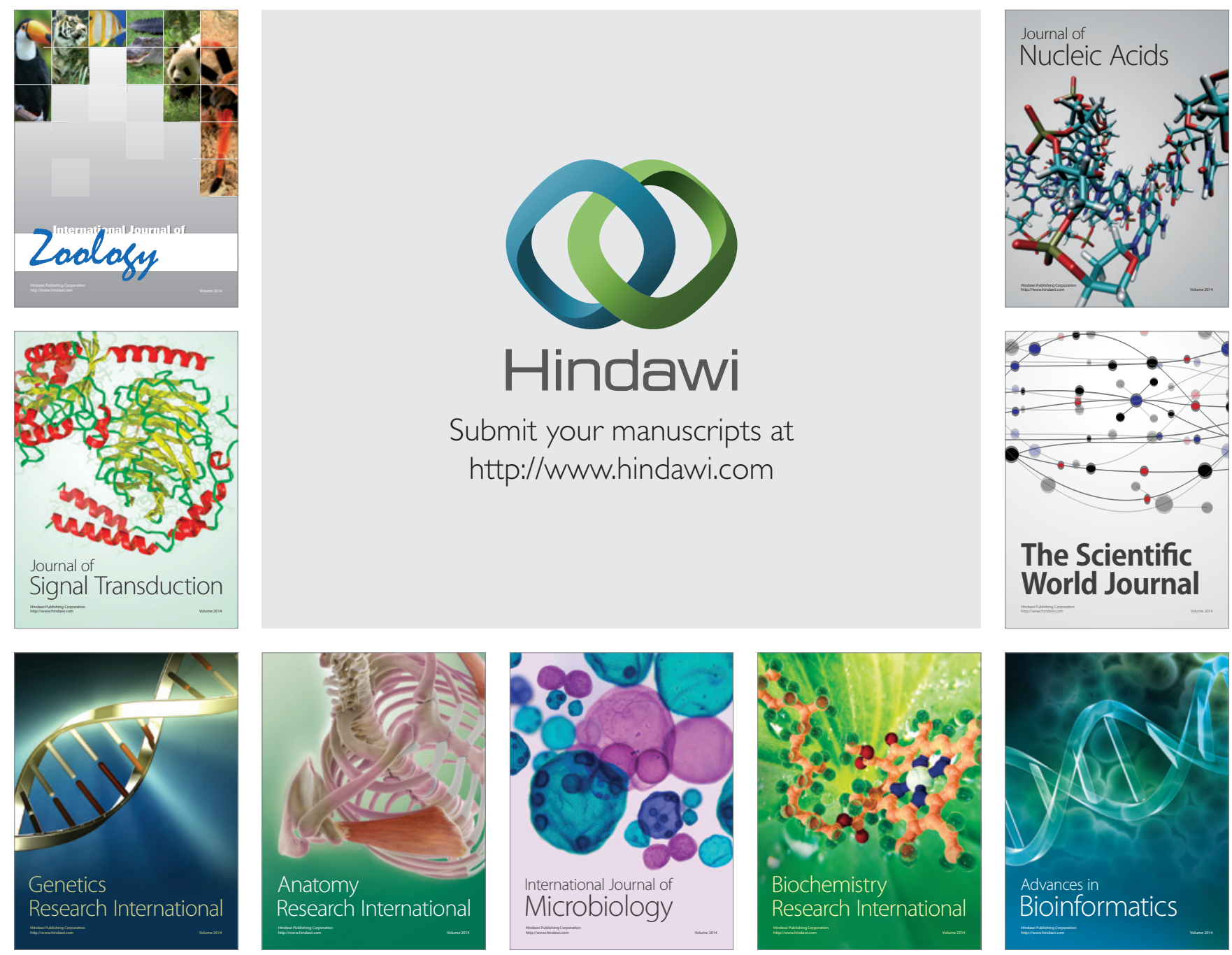

The Scientific World Journal
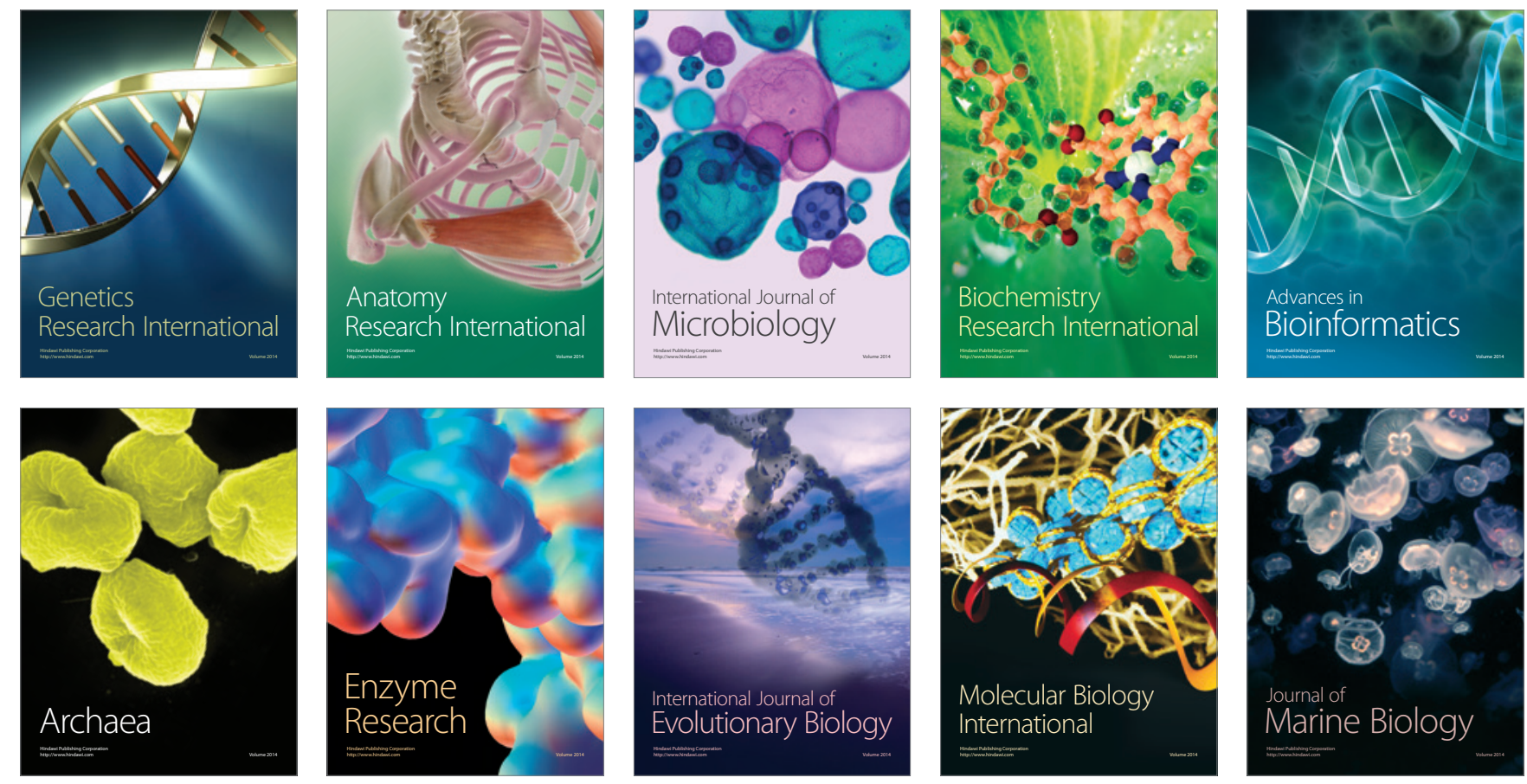